\title{
Thoracolumbar Fusion in Extreme Obesity: Complications and Patient-Reported Outcomes
}

\author{
JACOB R. JOSEPH, JENNIFER NEVA, BRANDON W. SMITH, MARY O. STRASSER, PAUL PARK \\ Department of Neurosurgery, University of Michigan, Ann Arbor, Michigan
}

\begin{abstract}
Background: Extreme obesity (class III) is defined by the Centers for Disease Control as a body mass index (BMI) value $\geq 40$. Recent studies suggest that obese patients have poor outcomes after thoracolumbar spinal fusions. The objective of this study was to analyze 30-day adverse events and patient-reported outcomes (PROs) for this population.

Patients and Methods: A retrospective chart review of spinal fusion surgeries performed at a single institution from 2006 to 2016 was executed. All patients had a preoperative BMI $\geq 40$. Patient characteristics, including age, sex, BMI, American Society of Anesthesiologists (ASA) score, Charlson Comorbidity Index (CCI), and others, were collected. Thirty-day adverse events (complications, readmissions, reoperations, and mortality) and PROs (Oswestry Disability Index [ODI] and visual analog scale [VAS]) were recorded.

Results: Fifty-six patients were identified, including 30 men (54\%). Mean age was 55.7 years (range, 31-74 years). Mean BMI was 44.2 (range, 40.0-54.7). Mean ASA was 2.7 (range, 2-3), and mean CCI was 1.1 (range, 0-6). Mean number of fused levels was 2.3 (range, 1-14). Mean length of stay was $4.4 \pm 2.1$ days. Mean number of complications was $0.7 \pm 1.1$, with $30.4 \%$ of patients having had at least 1 complication. The 30 -day all-cause readmission rate was $5.4 \%$, and 30 -day reoperation rate was $3.6 \%$. For 30 patients (54\%) with 1-year PROs, mean preoperative ODI was $65.2 \pm 11.1$, and mean preoperative VAS was $6.6 \pm 1.6$. Mean ODI change was $-19.9 \pm 20.1(P<.001)$, and mean VAS change was $-2.6 \pm 2.3(P<.001)$. A total of 15 patients $(50 \%)$ achieved the minimum clinically important difference in ODI (12.8), with a mean follow-up of 18.9 months.
\end{abstract}

Conclusions: Patients with extreme obesity who undergo thoracolumbar fusion have acceptable 30-day adverse events and potentially can achieve significant improvement in pain and disability.

Other \& Special Categories

Keywords: spinal fusion, obesity, class III obesity, extreme obesity, thoracolumbar fusion, patient-reported outcomes, spine surgery complications

\section{INTRODUCTION}

Obesity is an increasingly relevant problem in the modern spine surgery practice. ${ }^{1}$ The Centers for Disease Control and Prevention defines obesity as a body mass index (BMI) of 30 or greater, and it further subclassifies a BMI of 40 or greater as extreme obesity. ${ }^{2}$ Given the high prevalence of back pain and degenerative spine disease, in addition to the increasingly high rate of obesity, surgeons must often make decisions on the indications for intervention for patients who manifest both. However, spine surgery outcomes reported in the literature rarely include patients with extreme obesity. The aim of this retrospective study was to evaluate complications, reoperations, readmissions, and clinical outcomes after thoracolumbar fusion in extremely obese patients.

\section{PATIENTS AND METHODS}

After approval by the Institutional Review Board at the University of Michigan, a retrospective chart review of spinal fusion surgeries performed at a single institution from 2006 to 2016 was executed. Criteria for inclusion were a preoperative BMI $\geq 40$ and a spinal fusion involving the thoracic or lumbosacral segments. Patient characteristics, including age, gender, BMI, American Society of Anesthesiologists (ASA) score, Charlson Comorbidity Index (CCI), smoking status, preoperative narcotic use, and depression, were collected. Preoperative Oswestry Disability Index (ODI) and visual analog scale (VAS) scores were recorded. Surgical characteristics, including the indication for procedure, revision status, instrumented levels, and approach types, were documented. Details of surgical procedure, including the use of interbody 
fusion, osteotomies, and estimated blood loss, were collected. Thirty-day adverse events (complications, readmissions, reoperations, and mortality) as well as length of stay were recorded. A subgroup analysis of patients with patient-reported outcomes (PROs) between 6 and 24 months was also performed. Minimum clinically important difference (MCID) in ODI was previously defined for lumbar spine surgery as an improvement of $12.8 .^{3}$ Substantial clinical benefit (SCB) in ODI for lumbar arthrodesis was previously defined as an improvement of 18.8.

Statistical analysis was performed using GraphPad Prism software, version 6 (GraphPad Software Inc, La Jolla, California). Descriptive statistics were defined on 30-day adverse events. Paired 2-tailed $t$ tests were used to compare preoperative and postoperative BMI, ODI, and VAS in the subgroup analysis. A statistical significance level of $P<.05$ was set for this analysis.

\section{RESULTS}

A total of 56 patients were identified as having met the inclusion criteria. Mean age was $55.7 \pm 13.2$ years (range, 31-74 years), with 26 women (46\%) and 30 men $(54 \%)$. Mean preoperative BMI was $44.2 \pm 3.9$ (range, 40.0-54.7). Mean ASA was 2.7 (range, 2-3), and mean CCI was 1.1 (range, 0-6). Indications for surgery included spondylolisthesis (n $=20)$, spondylosis/degenerative disc disease $(n=19)$, pseudoarthrosis $(\mathrm{n}=7)$, degenerative scoliosis $(\mathrm{n}=$ $5)$, tumor $(\mathrm{n}=3)$, and trauma $(\mathrm{n}=2)$. A total of 7 patients $(13 \%)$ were current smokers, 41 (73\%) used narcotics preoperatively, and $29(52 \%)$ were being treated for depression. Baseline patient data are summarized in Table 1.

Mean number of fused levels was $2.3 \pm 2.1$ (range, 1-14). Mean estimated blood loss was 744.3 $\pm 924.4 \mathrm{~mL}$, and mean length of stay was $4.4 \pm 2.1$ days. Mean number of complications was $0.7 \pm 1.1$ (range, $0-4)$, and 17 patients $(30.4 \%$ ) had at least 1 complication. Complications included surgical site infection (4), durotomy (3), temporary peripheral neuropathy (3), hardware-related complications (2), deep venous thromboses or pulmonary embolism (2), urinary tract infection (2), acute kidney injury (2), intravascular line infection (1), urinary retention (1), intraoperative atrial fibrillation (1), hypotension requiring prolonged intensive care unit stay (2), worsened lymphedema (1), nosocomial pneumonia (1), pancreatitis (1), and retained surgical drain (1). The 30-day all-cause readmission rate was 5.4\%, and the 30-day reoperation rate was $3.6 \%$. There were no deaths within 30 days. Operative data and complications are summarized in Table 2.

In a subgroup analysis of 30 patients $(54 \%$ of all patients) with documented 1-year PROs, mean preoperative ODI was $65.2 \pm 11.1$, and mean preoperative VAS was $6.6 \pm 1.6$. Mean ODI change was $-19.9 \pm 20.1(P<.001)$, and mean VAS change was $-2.6 \pm 2.3(P<.001)$. Fifteen patients $(50 \%)$ achieved MCID in ODI with a mean follow-up of 18.9 months. A total of $14(46.7 \%)$ achieved SCB in ODI. Mean BMI was unchanged at 1-year followup $(P=.5)$. PROs are summarized in Table 3.

\section{DISCUSSION}

Because of perceived increased complication risk and potential decreased clinical benefit of surgery in the obese, many surgeons set BMI restriction criteria for elective surgery. Recently, the National Health Service in the United Kingdom denied or delayed surgery in certain situations for obese patients. ${ }^{5}$ However, the literature regarding complications and outcomes of spine surgery in obese patients is unclear, particularly in patients with extreme obesity.

Higgins et $\mathrm{al}^{6}$ evaluated the impact of obesity on complications after spinal fusion. They determined that there was a 2.8 times higher rate of wound complications in obese patients (BMI $\geq 30$ and $<40$ ) and a 10 times higher rate of wound complications in extremely obese patients (BMI $\geq 40$ ). Similarly, major medical complications were significantly higher in obesity, and more so in extreme obesity. In a subgroup analysis of thoracolumbar fusions, 18 patients with extreme obesity were included. There was a significant increase in wound complications, although other complications were not described. Similarly, a study by De la Garza-Ramos et $\mathrm{al}^{7}$ found that after lumbar fusion, obese patients had more complications. A subgroup analysis of patients with extreme obesity was not performed. National databases have also been used to evaluate complications after lumbar surgery, although they are known to have several limitations for spine surgery research. ${ }^{8,9}$ The American College of Surgeons National Surgical Quality Improvement Program (ACS NSQIP) was queried, and it was determined that extreme obesity was associated with a higher likelihood of complications, even when controlled for other comorbidities. ${ }^{10,11}$ MarquezLara et $\mathrm{al}^{12}$ similarly queried ACS NSQIP and 
Table 1. Baseline patient characteristics.

\begin{tabular}{lc}
\hline & Value \\
\hline Mean age, y & $55.7 \pm 13.2$ \\
Mean BMI, kg/m² & $44.2 \pm 3.9$ \\
Male, n (\%) & $30(54)$ \\
Mean ASA score & $2.7 \pm 0.5$ \\
Mean CCI score & $1.1 \pm 1.6$ \\
Current smoker, n (\%) & $7(13)$ \\
Depression, n (\%) & $29(52)$ \\
Preoperative narcotics, n (\%) & $41(73)$ \\
\hline
\end{tabular}

Abbreviations: ASA, American Society of Anesthesiologists; BMI, body mass index; CCI, Charlson Comorbidity Index.

found a stepwise relationship of complications with increasing obesity classes, although a mortality difference was not seen. However, other studies have not seen a difference in complication rates in obese patients. A study evaluating lateral lumbar fusions reported no difference between obese (BMI $\geq 30$ ) and nonobese patients. ${ }^{13} \mathrm{Fu}$ et al ${ }^{14}$ also found no difference when comparing complication rates after deformity correction.

Functional and pain outcomes after lumbar fusion in the extremely obese are also unclear. Giannadakis et $\mathrm{al}^{15}$ prospectively evaluated patients after decompressive lumbar surgery and determined that both obese and nonobese patients had significant improvement in ODI, although obese patients were less likely to achieve MCID. Terman et $\mathrm{al}^{16}$ found that obese patients had a significant decrease in ODI after transforaminal lumbar interbody fusion with either an open (13-point ODI decrease) or minimally invasive (15-point ODI decrease) approach. Djurasovic et $\mathrm{al}^{17}$ also found that obese patients had results similar to those of nonobese patients, achieving a 14-point decrease in ODI 2 years after lumbar fusion. BMI was not seen to be an independent predictor of worse PROs at 1 year in another analysis. ${ }^{18}$ These studies did not specifically investigate the outcomes of extremely obese patients.

In the present study, extremely obese patients with PROs at 1 year had a 19.9-point decrease in ODI and a 2.6-point decrease in VAS. This is comparable to previously reported outcomes in

Table 2. Operative data and complications.

\begin{tabular}{lc}
\hline & Value \\
\hline Number of fused levels (range) & $2.3 \pm 2.1(1-14)$ \\
Estimated blood loss, mL & $744.3 \pm 924.4$ \\
Length of stay, d & $4.4 \pm 2.1$ \\
Mean number of complications & $0.8 \pm 1.2$ \\
Surgical site infection, n (\%) & $4(7.1)$ \\
30-day all-cause readmissions, n (\%) & $3(5.4)$ \\
30-day reoperations, n $(\%)$ & $2(3.6)$ \\
\hline
\end{tabular}

Table 3. Subgroup analysis of patient-reported outcomes at 1 year.

\begin{tabular}{lccc}
\hline & Preoperative & $\mathbf{1 ~ y}$ & $\boldsymbol{P}$ Value \\
\hline ODI & $65.2 \pm 11.1$ & $45.3 \pm 21.3$ & $<.001$ \\
VAS & $6.6 \pm 1.6$ & $4.0 \pm 1.9$ & $<.001$ \\
\hline
\end{tabular}

Abbreviations: ODI, Oswestry Disability Index; VAS, visual analog scale.

obese and nonobese patients. ${ }^{15,19,20}$ In addition, $50 \%$ achieved MCID, and $46.7 \%$ achieved SCB. Readmission and reoperation rates were found to be appropriately low in the cohort. These results suggest that even with extreme obesity, patients can have adequate outcomes after thoracolumbar fusion. Previous literature suggests that these results are sustainable in the long term. ${ }^{19}$ A total of $30 \%$ of patients did have at least 1 complication, although most complications were minor. Notably, only 4 patients $(7 \%)$ had surgical site infections. Although these results, along with previous literature, show that extreme obesity is associated with higher complication rates, the risks may be tolerable in light of an established benefit of surgery. ${ }^{11,18}$ Overall, the results presented here suggest that a defined BMI cutoff is too arbitrary, and selected patients with elevated BMIs should not be absolutely prohibited from spine surgery. ${ }^{1}$

There are several limitations to this study. We did not have a direct control group to judge the effect that extreme obesity bore on surgical outcomes. In addition, there were a number of patients for whom 1-year PROs were not available, which may have altered the results. Finally, this was a retrospective study and is subject to the known limitations and biases of retrospective analysis.

\section{CONCLUSION}

Patients with extreme obesity who undergo thoracolumbar fusion have acceptable 30-day adverse events and can potentially derive significant benefit in reduced pain and disability.

\section{REFERENCES}

1. Jackson KL 2nd, Devine JG. The effects of obesity on spine surgery: a systematic review of the literature. Global Spine J. 2016;6(4):394-400.

2. Centers for Disease Control and Prevention. Defining adult overweight and obesity. https:/www.cdc.gov/obesity/ adult/defining.html. Accessed January 8, 2019.

3. Copay AG, Glassman SD, Subach BR, Berven S, Schuler TC, Carreon LY. Minimum clinically important difference in lumbar spine surgery patients: a choice of methods using the Oswestry Disability Index, Medical Outcomes Study question- 
naire Short Form 36, and pain scales. Spine J. 2008;8(6):968974.

4. Glassman SD, Copay AG, Berven SH, Polly DW, Subach BR, Carreon LY. Defining substantial clinical benefit following lumbar spine arthrodesis. J Bone Joint Surg Am. 2008;90(9):1839-1847.

5. BBC News. Obese patients denied surgery in a third of areas of England. http://www.bbc.com/news/health-36101302. Accessed April 5, 2017.

6. Higgins DM, Mallory GW, Planchard RF, et al. Understanding the impact of obesity on short-term outcomes and in-hospital costs after instrumented spinal fusion. Neurosurgery. 2016;78(1):127-132.

7. De la Garza-Ramos R, Bydon M, Abt NB, Sciubba DM, Wolinsky JP, Bydon A, et al. The impact of obesity on shortand long-term outcomes after lumbar fusion. Spine (Phila Pa 1976). 2015;40(1):56-61.

8. Golinvaux NS, Bohl DD, Basques BA, Fu MC, Gardner EC, Grauer JN. Limitations of administrative databases in spine research: a study in obesity. Spine J. 2014;14(12):29232928.

9. Joseph JR, Smith BW, Park P. Variability in standard outcomes of posterior lumbar fusion determined by national databases. World Neurosurg. 2017;97:236-240.

10. Buerba RA, Fu MC, Gruskay JA, Long WD 3rd, Grauer JN. Obese class III patients at significantly greater risk of multiple complications after lumbar surgery: an analysis of 10,387 patients in the ACS NSQIP database. Spine $J$. 2014;14(9):2008-2018.

11. Seicean A, Alan N, Seicean S, Worwag M, Neuhauser D, Benzel EC, et al. Impact of increased body mass index on outcomes of elective spinal surgery. Spine (Phila Pa 1976). 2014;39(18):1520-1530.

12. Marquez-Lara A, Nandyala SV, Sankaranarayanan S, Noureldin M, Singh K. Body mass index as a predictor of complications and mortality after lumbar spine surgery. Spine (Phila Pa 1976). 2014;39(10):798-804.

13. Adogwa O, Farber SH, Fatemi P, Desai R, Elsamadicy A, Cheng J, et al. Do obese patients have worse outcomes after direct lateral interbody fusion compared to non-obese patients? $J$ Clin Neurosci. 2016;25:54-57.

14. Fu L, Chang MS, Crandall DG, Revella J. Does obesity affect surgical outcomes in degenerative scoliosis? Spine (Phila Pa 1976). 2014;39(24):2049-2055.

15. Giannadakis C, Nerland US, Solheim O, et al. Does obesity affect outcomes after decompressive surgery for lumbar spinal stenosis?: a multicenter, observational, registry-based study. World Neurosurg. 2015;84(5):1227-1234.

16. Terman SW, Yee TJ, Lau D, Khan AA, La Marca F, Park P. Minimally invasive versus open transforaminal lumbar interbody fusion: comparison of clinical outcomes among obese patients. J Neurosurg Spine. 2014;20(6):644-652.

17. Djurasovic M, Bratcher KR, Glassman SD, Dimar JR, Carreon LY. The effect of obesity on clinical outcomes after lumbar fusion. Spine (Phila Pa 1976). 2008;33(16):1789-1792.

18. Sielatycki JA, Chotai S, Stonko D, et al. Is obesity associated with worse patient-reported outcomes following lumbar surgery for degenerative conditions? Eur Spine J. 2016;25(5):1627-1633.

19. Adogwa O, Elsamadicy AA, Han JL, Cheng J, Karikari I, Bagley CA. Do measures of surgical effectiveness at 1 year after lumbar spine surgery accurately predict 2-year outcomes? J Neurosurg Spine. 2016;25(6):689-696.

20. Asher AL, Chotai S, Devin CJ, Speroff T, Harrell FE Jr, Nian $\mathrm{H}$, et al. Inadequacy of 3-month Oswestry Disability Index outcome for assessing individual longer-term patient experience after lumbar spine surgery. J Neurosurg Spine 2016;25(2):170-180.

Disclosures and COI: Dr Park is a consultant for and receives royalties from Globus. He is also a consultant for Medtronic, Zimmer-Biomet, and NuVasive. Drs Joseph, Smith, Neva, and Strasser have no disclosures. This research did not receive any specific grant from funding agencies in the public, commercial, or not-for-profit sectors.

Corresponding Author: Paul Park, MD, Department of Neurosurgery, University of Michigan, 1500 East Medical Center Dr, Room 3553 TC, Ann Arbor, MI 48109-5338. Phone: (734) 615-2627; Email:ppark@med.umich.edu

Published 22 February 2019

This manuscript is generously published free of charge by ISASS, the International Society for the Advancement of Spine Surgery. Copyright (C) 2019 ISASS. To see more or order reprints or permissions, see http://ijssurgery.com. 